\title{
RETRACTED ARTICLE: Modular framed vertex operator algebras
}

\author{
Chongying Dong ${ }^{1,2}$. Ching Hung Lam $^{3,4}$. \\ Li $\operatorname{Ren}^{1}$
}

The authors have retracted this article because they found an error in the proof of the main theorem. Authors have identified that there is not sufficient proof of statement: "In particular, $V_{D}^{d}$ is a free D-module." Therefore the main theorem is not reliable. All authors agree to this retraction.

Publisher's Note Springer Nature remains neutral with regard to jurisdictional claims in published maps and institutional affiliations.

Electronic supplementary material The online version of this article (https://doi.org/10.1007/s40879018-0257-6) contains supplementary material, which is available to authorized users.

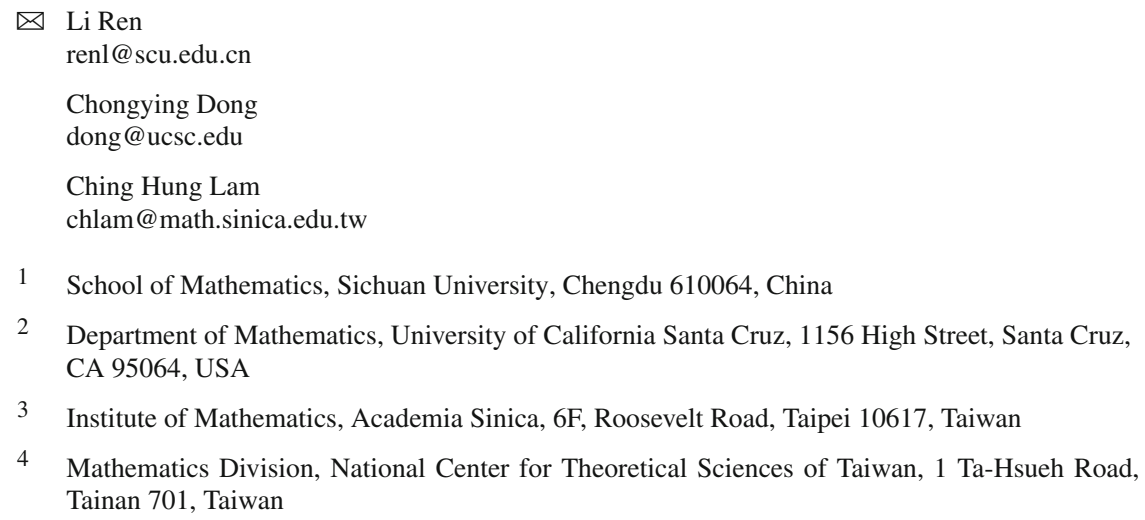

